\title{
Estudo eletroforético da dinâmica de variaçào genética em três taxa ribeirinhos ao longo do rio Solimōes, América do Sul
}

\author{
Robert J. Hill (') \\ Ghillean T. Prance (') \\ Scott A. Mori ${ }^{(2)}$ \\ William C. Steward (') \\ Darcy Shimabukuru \\ João Bernardi ${ }^{(3)}$
}

Resumo

Ao longo de um trecho de $2.174 \mathrm{~km}$ do rio Solimōes, partindo de Iquitos. Peru, a Manaus, Brasil, foi realizado um estudo eletroforético para determinação da quantidade de variação genética em três taxa de leguminosas (Aeschynomene sensitiva Sw. var. amazonica Rudd, Papilionoideae; Mimosa Pigra L., Mimosoideae). A variabilidade genética foi expressa em termos de: 1) grau de polimorfismo enzimático $\left(\mathrm{P}^{\prime}\right)$, e 2) heterozigosidade populacional média $\left(\mathrm{H}^{\prime}\right)$. Foram examinados cinco sistemas enzimáticos: leucina-aminopeptidase (LAP), glutamato-dehidrogenase (GDH), fosfoglucomuta. se (PGM), fosfoglucoisomerase (PGI), e fosfatase ácida $(\mathrm{AcPH})$. Os taxa ribeirinhos apresentam condiçōes excepcionais para estudos experimentais sobre biologia de população e evolução. A origem, perpetuação e dinâmica de variação gênica intra e interpopulacional são usadas como indicadores de mudança evolutiva. O fluxo gênico entre essas leguminosas entomolfilicas e dispersas na água é unidirecional e linear, com fluxo regressivo mínimo por vetores de pólen. Entre as enzimas examinadas, LAP foi um monômero para todos os três taxa, com valores polimórficos baixos. AcPH, outro monômero codominante, não apresentou fração isoenzimática detectável, situaçāo semelhante à encontrada em sistemas PGM. PGI é um sistema muito complexo controlado por diversos loci. GDH é monomórfico, com uma faixa detectável. O polimorfismo médio para os dois taxa de Aeschynomene é $21.3 \%$ ( $\mathrm{P}^{\prime}=$ $0.213)$, e para Mimosa é $24 . \%\left(P^{\prime}=0.245\right)$. A heterozigosidade populacional média (estatística $\mathrm{Nei} \mathrm{H}^{\prime}$ ) variou entre 0.10 e 0.43 para Aeschynomene. Esse valor foi significativamente maior para Mimosa, variando entre 0.33 e 0.50 . Os indices de heterozigosidade $\mathrm{e}$ de similaridade genética, os padrōes demográficos e a biologia, indicam uma estreita correlaçāo entre a variabilidade genética e a estratégia adaptativa. As populações com alta probabilidade de extinção são mais homozigóticas do que aquelas com maior probabilidade de sobrevivência. A homozigosidade é favorecida em populaçōes que sofrem perturbaçōes ao longo do rio Solimões.

\section{INTRODUÇÃO}

As espécies ribeirinhas formam um sistema experimental ótimo para o estudo do fluxo genético e da dinâmica da variação genética. A origem, a perpetuação e a dinâmica de variação gênica intra e inter-populacional podem ser usadas como indicadores de mudança evolutiva. Três taxa da família Leguminosae foram examinados por meio de eletroforese para estabelecimento do grau de polimorfismo enzimático e de heterozigosidade populacional média. Os dados obtidos fundamentam extrapolações sobre mudanças evolutivas e estratégias adaptativas. Os taxa examinados foram: Aeschynomene sensitiva Sw. var. sensitiva (Fig. 9 e 11), Aeschynomene sensitiva Sw. var. amazonica Rudd (Fig. 6) Papilionoideae; e Mimosa pigra L. (Fig. 10), Mimosoideae. O fluxo genético entre essas plantas entomófilas e dispersas nas águas do rio Solimỏes é unidirecional e linear, com fluxo regressivo mínimo por vetores de pólen.

O gênero Aeschynomene está predominantemente distribuído nas regiōes tropicais do mundo (Rudd, 1955). A Aeschynomene sensitiva var. sensitiva encontra-se diferenciada nos valores colombianos de Cauca e Magdalena, e na Amazônia peruana-brasileira. A variedade típica está distribuida em habitats úmidos do Caribe (Fig. 1), sul do México, América Central e do Sul (Fig. 2). A Aeschynomene sensitiva var. amazonica é encontrada ao

(1) - New York Botanical Garden, Bronx, NY 10458 - USA.

(2) - Comissão Executiva do Plano da Lavoura Cacaueira, Diretoria Científica, Caixa Postal 7, 45.600, Itabuna, BA Brasil.

(3) - Instituto Nacional de Pesquisas da Amazônia. 


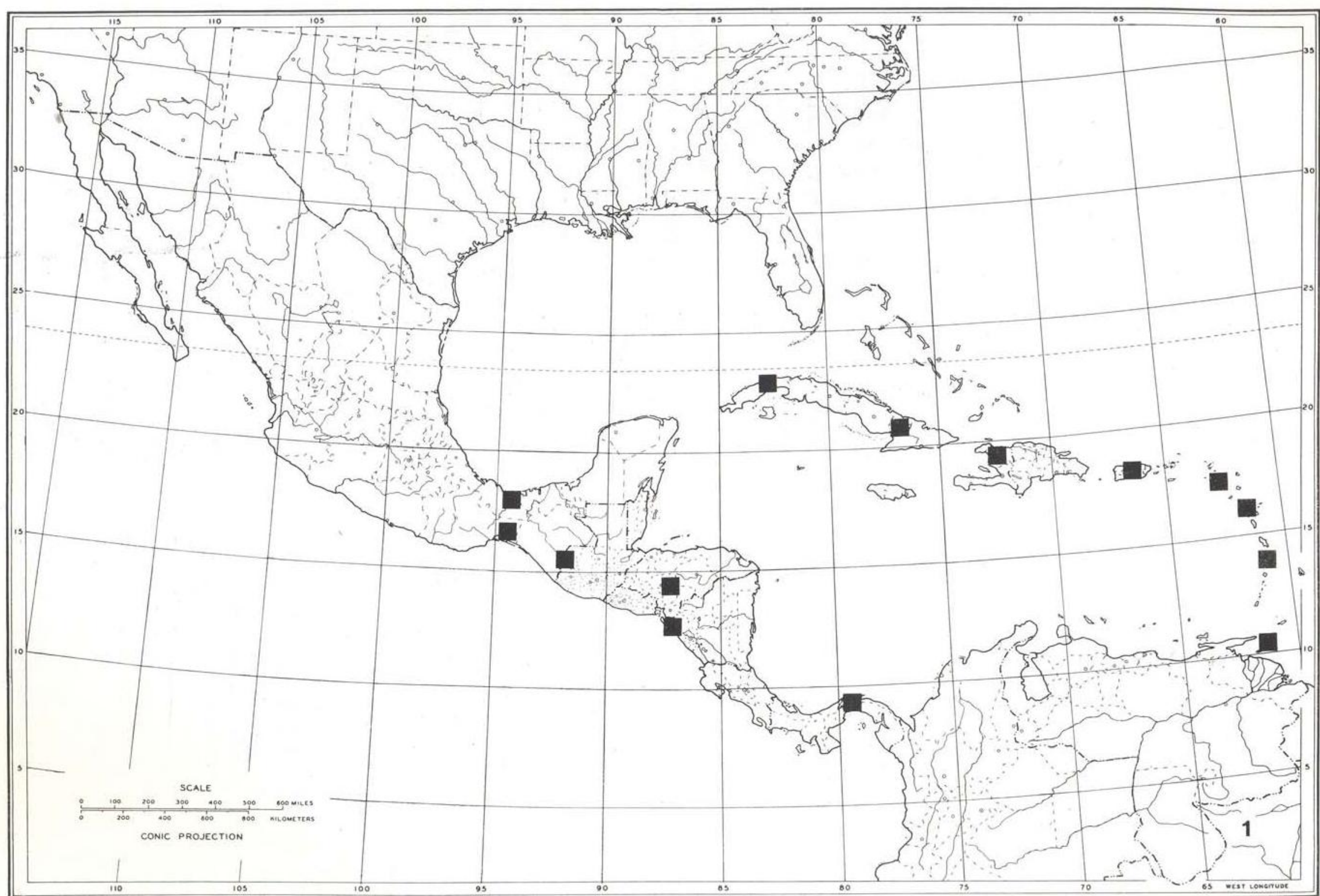


longo do rio Solimões (Fig. 3). Embora a herborização cause o desaparecimento de muitos traços distintivos entre os exemplares de herbário, no campo foi facilmente observado que a biologia, a história de vida e alguns caracteres fenotípicos são suficientemente diferentes para permitir pelo menos o reconhecimento das variedades. Os caracteres úteis para a distinção entre as duas variedades de Ae. sensitiva estão relacionados na Tabela 1. Mimosa pigra também é um taxon amplamente distribuido em vários habitats tropicais úmidos e de vegetação secundária, claramente distinto de todas as outras Mimosoideae da região amazônica.

\section{MATERIAIS E MÉTODOS}

Vinte e seis populações de três taxa dispersos ao longo de um trecho de 2.174 quilômetros do rio Solimões, de Iquitos, Peru, a Manaus, Brasil, foram examinados por meio de eletroforese. Os dados sobre os locais, números de coleta e designações de populações encontram-se na Tabela 2. Foram examinados quatrocentos miligramas de sementes de cada cinco indivíduos de todas as populações. Existe certa preocupação a respeito da validade da técnica de amostragem. A mistura de sementes provenientes de uma única planta foi necessária pois uma semente era insuficiente para produzir resultados. O limitado tempo a bordo não permitiu a germinação das sementes e é fato conhecido que os melhores resultados são alcançados quando se usa plantas jovens. Os autores estão cientes de que a constituição genética de uma mistura de sementes de uma planta mostra todos os genes que afetam os megasporângios segregados dos pais, mais uma conglomeração de seus alelos existentes na população. Em populações homogêneas não há problemas. Nas populações heterogêneas e panmíticas os resultados são, entretanto, uma estimativa, já que está representada neles uma coleção ao acaso dos genes da população que se manifestam nos microsporângios.: Quanto maiores forem a autocompatibilidade e a autofecunda-' ção de uma espécie, maior será a segurança desta técnica de amostragem. A eletroforese foi feita por meio do Sistema Canalco, a bordo do navio Alpha Helix, do Scripps Institution of Oceanography, Fase VI - Expedição Amazônica. No laboratório Harding do New Yark Botanical Garden foram realizados testes de confiança sobre placas de gel para assegurar a precisão dos valores $\mathrm{Rp}$. As soluçōes químicas utilizadas no presente estudo são as descritas por Ornstein (1964) e Davis (1964). Os procedimentos de análise foram relatados por Hill (1977). Os resultados foram fotografados e anotados para posterior análise matemática. Cinco sistemas enzimáticos foram examinados: leucina-aminopeptidase (LAP, EC 3.4.1.1)3, glutamato-dehidrogenase (GDH, EC 1.4.1.2), fosfoglucomutase (PGM, EC 2.7.5.1), fosfoglucoisomerase (PGI, EC 5.3.1.9), e fosfatase ácida (AcPH, EC 3.1.3.2). Conforme pode ser determinado através do primeiro dígito do número da Comissão Enzimática, as enzimas representam diversas classes de moléculas: oxidoreductases, transferases, hidrolases e isomerases. Todos os testes são estandardizados, previamente publicados. LAP L-leucyl-beta-naphthylamide. Sais diazonium perdem o naphthol liberado pela divisão enzimática. O teste LAP utilizado foi descrito por Gottlieb (1973a). Outra enzima hidrolética não-específica examinada foi a $\mathrm{AcPH}$. Para esse sistema foi usado um substrato artificial, fosfato ácido alphanaphthyl. Os sais diazonium prendem o naphtol e formam o corante marcador (Maclntyre, 1966). O sistema químico usado para AcPH foi descrito por Gottlieb (1973a). GDH (óxido redutase), catalizando a interconversão de glutamato e cetoglutarato, é conhecido como um elo importante entre o metabolismo de aminoácido e o metabolismo de carbohidrato (Dickinson e Sullivan, 1975). A metodologia usada para o teste GDH foi a descrita por Gottlieb (1973b). PGM (transferase) utiliza glucose-1-fosfato como um substrato e combina o produto, glucose-6-fosfato, a um sistema de redução de tetrazolium através de glucose-6-fosfato dehidrogenase (Hjorih, 1970; Trippa et al., 1970). PGI (isomerase) é similar a PGM, mas incorpora frutose-6-fosfato como substrato. O teste PGI foi o mesmo descrito por Gottlieb (1973b). 


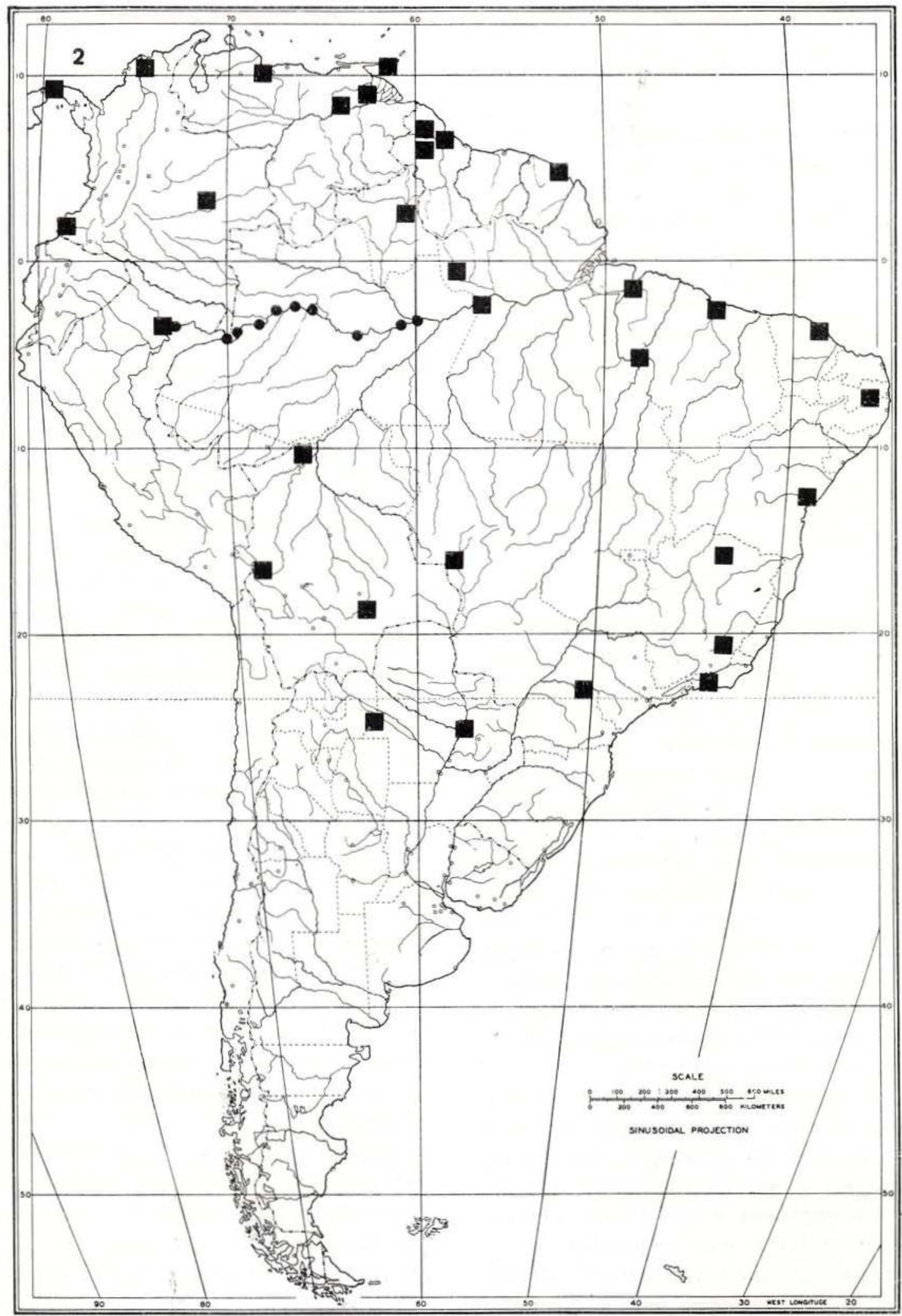

Fig. 2 - Mapa da distribuiçåo de Aeschynomene sensitiva var. sensitiva nas Américas Central e do Sul. Os quadrinhos representam dados derivados de Rudd (1955) e do Herbário ( $\mathrm{Ny}$ ). Os círculos representam localidades ao longo do rio Solimões, utilizadas no presente trabalho (ver Tabela 1). 


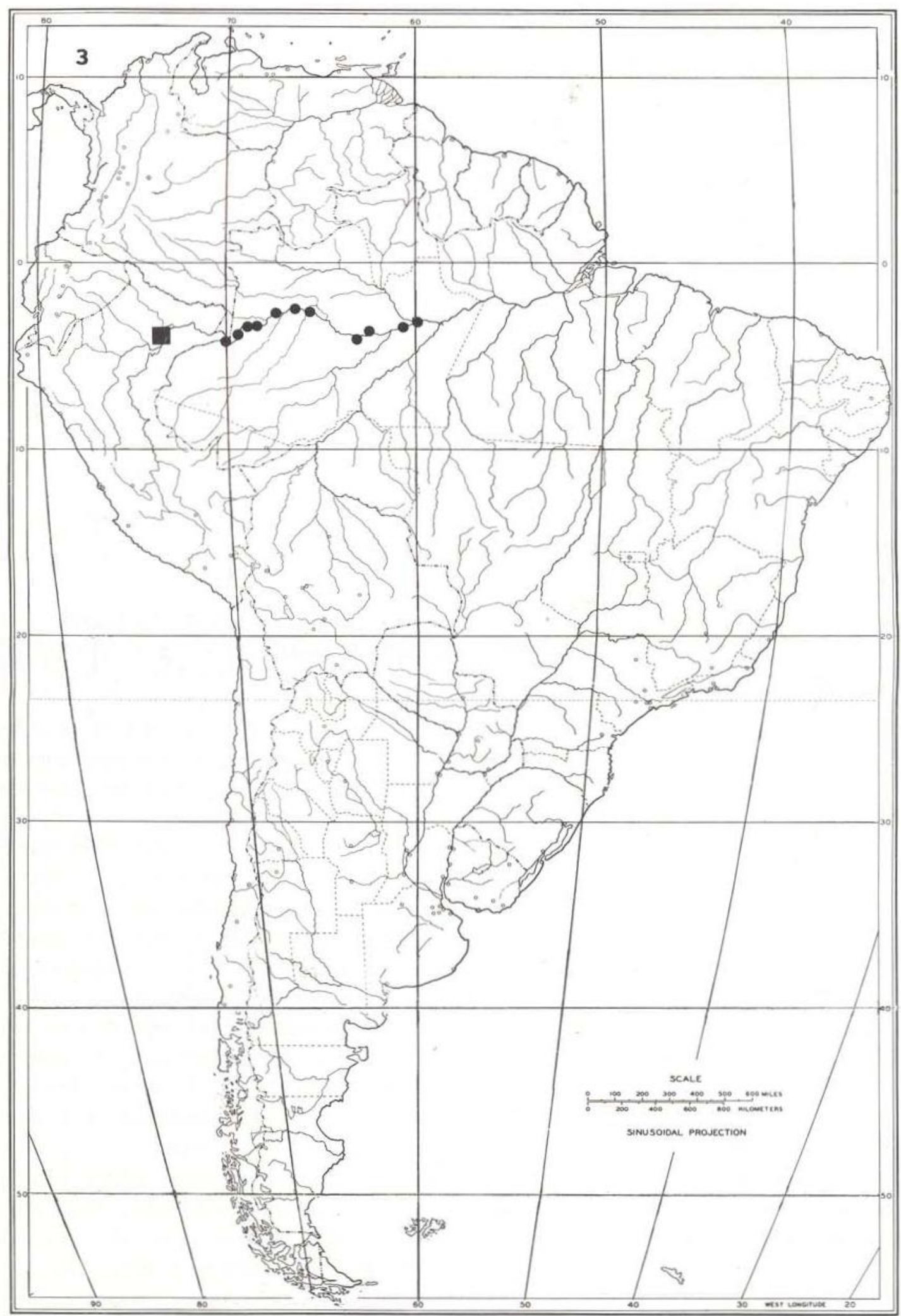

Fig. 3 - Mapa da distribuição de Aeschynomene sensi tiva var. amazonica ai longo do rio Solimōes. Os quadrinhos representam dados derivados de Rudd (1955) e do Herbário (NY). Os círculos representam as localidautilizadas no presente trabalho (ver Tabela 1). 
As freqüências gênicas foram calcuiadas a partir dos dados brutos (Tabela 3). Esses dados foram usados para calcular a heterozigose de um locus (Selander, 1976): $H=1.0-x_{i}^{2}$, onde $x_{i}$ é a freqüência do alelo $\mathrm{i} \stackrel{\circ}{=}$. A heterozigose populacional média $\left(\mathrm{H}^{\prime}\right)$ foi calculada através da seguinte equação:

$$
H=\frac{H \text { médio }}{\text { número total de loci }}
$$

É importante lembrar que a extrapolação a partir de pequenos conjuntos de loci para genomas é arriscada (Selander \& Kaufman, 1973); entretanto, é a melhor aproximação disponivel.

A identidade e a distância genética foram calculadas para cada locus através de estatísticas formuladas por Nei (1972). Se A e B são duas populações diferentes, e L é um locus determinado, a probabilidade normalizada de que os dois alelos, um de cada população, sejam idênticos é:

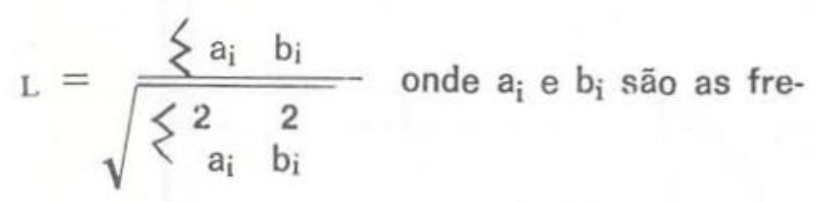

qũências do alelo $i^{\circ}=$ nas populaçōes $A$ e B. A identidade genética média de todos os loci estudados é dada pela equação:

$\mathrm{I}=\frac{\mathrm{lab}}{\sqrt{\mathrm{I}_{\mathrm{a}} \cdot \mathrm{I}_{\mathrm{b}}}}$ onde $\mathrm{I}_{\mathrm{ab}}$ é a média aritmética, incluindo todos os loci, de $\sum a_{i} b_{i}$; e $\mathrm{I}_{\mathrm{a}}$ e $\mathrm{I}_{\mathrm{b}}$ são as médias aritméticas, incluindo todos os loci, de $\sum a_{i} 2$ e $\sum b_{i} 2$, respectivamente. A distância genética é então definida como:

$$
D=-\log _{e} I
$$

Os desvios-padrões foram calculados pela equação de Zouros (1973):

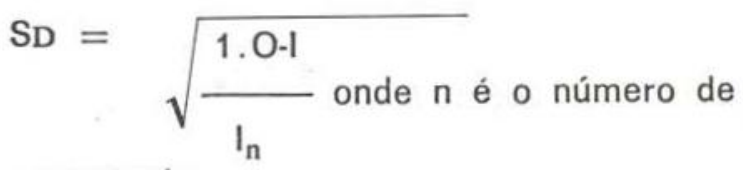

loci examinados.

O polimorfismo enzimático foi calculado segundo Johnson (1971):

$$
P=\frac{\sum f_{i} x_{i}}{\sum x_{i}} \text { onde, para a amostra } i, f
$$

é a freqüência do alelo mais comum $\mathrm{e} x$ é $o$ tamanho da amostra. O valor $(1,0-P)$ é um indice de polimorfismo ( $\left.\mathrm{P}^{\prime}\right)$. Um locus é considerado polimórfico numa população se a freqüência do eletromorfo mais comum for 0,99.

\section{RESULtados}

ELETROFORESE E HETEROZIGOSIDADE POPULACIONAL

O LAP para todos os três taxa foi monomérico, apresentando uma zona com um alelo rápido e um lento. Variantes isoenzimáticos foram encontrados nas populações de número 7 (Ae. sensitiva var. sensitiva), 16 (Ae. sensitiva var. amazonica) e 25 (Mimosa pigra). GDH foi monomórfico, apresentado somente uma densa faixa de $\mathrm{Rp}$ resolúvel valendo 0,068 . Lee \& Fairbrothers (1973) mostraram que as plântulas de Typha também são monomórficas. Isto pode representar uma enzima monomérica ou pode ser um artefato. Algumas enzimas tendem a se ligar mais fortemente que outras e, então, não são detectáveis sob alguns regimes eletroforéticos (Harris, et al., 1974). PGM e AcPH são monómeros codominantes e não apresentam frações isoenzimáticas detectáveis. Os zimogramas revelaram duas faixas distintas em heterozigotes e uma faixa, de ambas mobilidades, em homozigotes. PGI provou ser bastante complexo e é aparentemente controlado por diversos loci. Há considerável interação genética. Em algumas populações apareceram até oito faixas (e.g. população 8), 


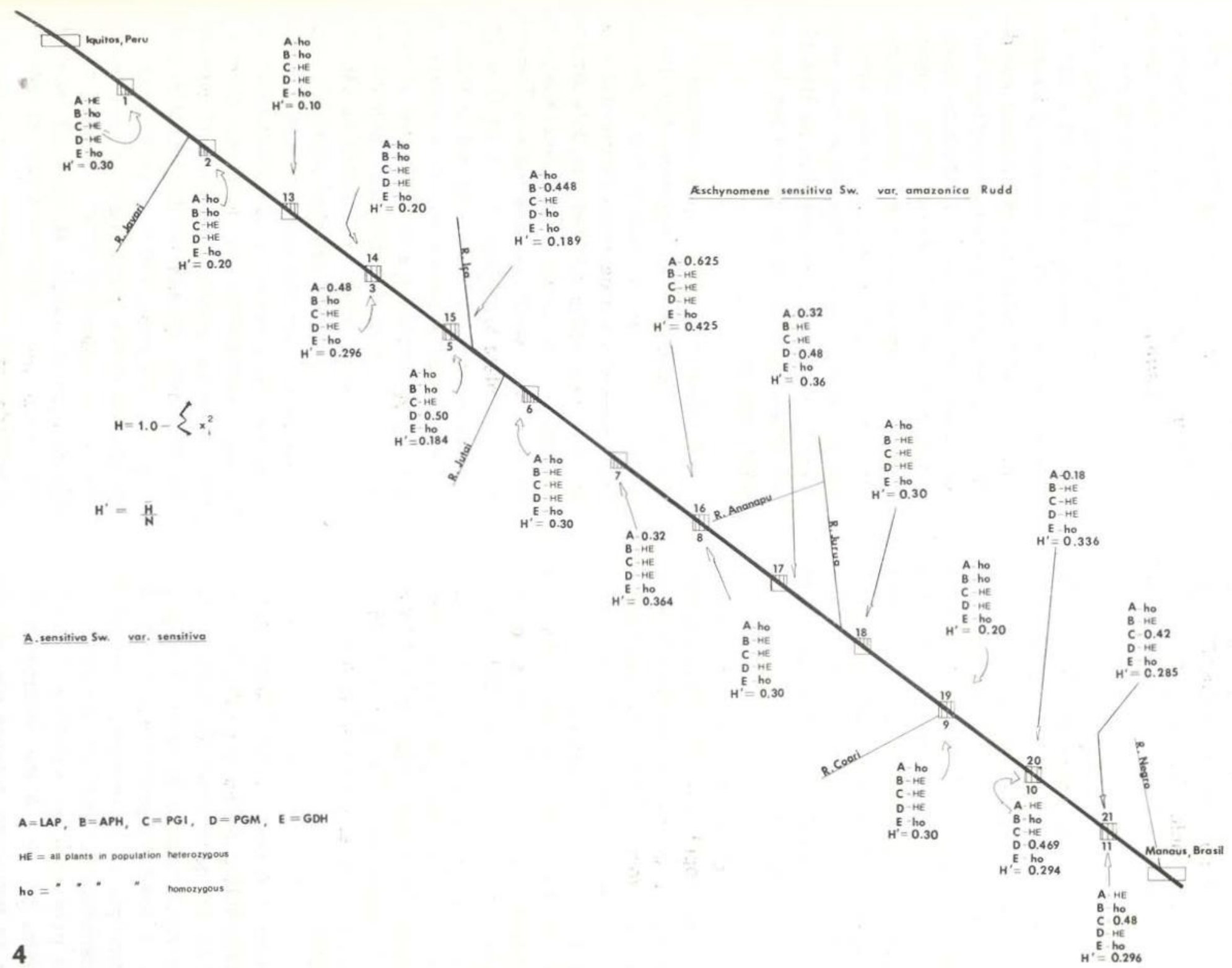

Fig. 4 - Representaçăo diagramática do rio Solimōes, de lquitos, Peru, a Manaus, Brasil. H' é a heterozigosidade populacional média. H (heterozigose de um \& mene sensitiva var. amazonica, e abaixo são de Ae. sensitiva var. sensitiva. 
embora o mais comum tenha sido o aparecimento de três faixas. Enquanto não forem realizados experimentos complementares de fecundação a significância do izmograma do PGI só pode ser conjeturada, e não será discutida em detalhes no presente trabalho. Uma zona de migração rápida foi decifrável e está relatada na tabela de freqüência gênica (Tabela 3).

A Figura 4 é uma representação diagramática do trecho de $2.174 \mathrm{~km}$ do rio Solimões, de Iquitos, Peru, a Manaus, Brasil. O comprimento total do rio Solimões-Amazonas é de aproximadamente $5.500 \mathrm{~km}$ (Marlier, 1973). As amostragens foram tiradas antes e depois da entrada dos principais afluentes. As junções são regiões onde há possibilidade de chegada de material genético novo de cima do rio, e de perturbação das populações, devido às enchentes sazonais.

Os valores de heterozigosidade média (H') para cada população são apresentados, assim como as taxas de heterozigose/homozigose para cada locus. Todas as populações acima da diagonal são de Aeschynomene sensitiva var. amazonica, e abaixo são de Ae. sensitiva var. sensitiva. Mimosa pigra não está representada no diagrama. Os valores de heterozigosidade média variam de 0,184 a 0,364 para a var. sensitiva, 0,10 a 0,425 para a var. amazonica, e 0,33 a 0,50 para Mimosa (Tabela 4). A heterozigosidade média de muitas populações de organismos é de 5 a $15 \%$ do valor de seus loci $\left(\mathrm{H}^{\prime}=0,05\right.$ a $\mathrm{H}^{\prime}=0,15$ ) (Selander, 1976).

A Figura 5 é uma representaçãn gráfica da heterozigosidade média em relação à distância do rio, em quilômetros, de lquitos a Manaus. Ao descer alguns afluentes é possivel notar que a heterozigosidade inicialmente decresce, com gradual acumulação (aumento na heterozigosidade) de material genético. Isto é evidente para a var. sensitiva, nas confluências de todos os rios. A var. amazonica não apresenta ăs flutuações cíclicas que são evidentes na var. sensitiva. Nos rios Içá e Jutaí (tributários) não há mudança heterozigótica detectável. Somente abaixo da boca do rio Juruá há um decréscimo na heterozigosidade. com um aumento após o rio Coari.

$O$ indice de polimorfismo varia em diferentes sistemas enzimáticos (Tabela 5). 0 polimorfismo médio entre todas as populações da var. sensitiva é 23,8\%; para a var. amazonica é $18,8 \%$, e para Mimosa é $24.5 \%$. As populações de muitos organismos são polimórficas (para eletromorfos) em 10 a $50 \%$ de seus loci (Selander, 1976; Selander \& Kaufman, 1973). Existem relativamente poucos estudos sobre diferenciação protéica (genética) entre populações de plantas estreitamente relacionadas (Gottlieb, 1976; Ayala, 1976). Entretanto, quando comparados com valores conhecidos para animais, os $\mathrm{H}^{\prime}$ das plantas amazônicas são altos, enquanto que os ' $\mathrm{P}^{\prime}$ são semeIhantes. As populações de todos os três taxa são heterozigóticas, porém pobres em frações isoenzimáticas.

Os cálculos da identidade genética (1) e distância genética (D), segundo Nei (1972), estão relacionados nas Tabelas 6 e 7 . As identidades genéticas existentes dentro das e entre as combinações gênicas dos dois Aeschynomene foram examinadas. Aeschynomene sensitiva var. sensitiva teve valores $T$ variando de completa identidade, $\bar{T}=1.00, \bar{D}=0.00$ (populaçōes de 1 a 5 e 6 a 9), a $I=0,853 \pm$ 0,171 , quando a população 10 é comparada com as populações 6 e 9 . Em geral as populações 6, 7 e 9 são diferenciadas (geneticamente dispares) de outras populações da var. sensitiva. A identidade genética média de todos os pares da var. sensitiva é $0,926 \pm 0,122$. Aeschynomene sensitiva var. amazonica é um pouco mais variável geneticamente do que a var. sensitiva, com a população 17 apresentando a maior quantia de diferenciação genética. As diferenças entre as populações $13 \mathrm{e}$ 17 são aparentes, considerando-se o baixo valor de identidade $(\bar{l}=0,738 \pm 0,228)$. A identidade genética média de todos os pares da var. amazonica é 0,892 $\pm 0,147$. O valor de identidade entre os conjuntos gênicos dos dois taxa é $0,902 \pm 0,140$. As diferenças na identidade entre os dois taxa não são estatistica- 


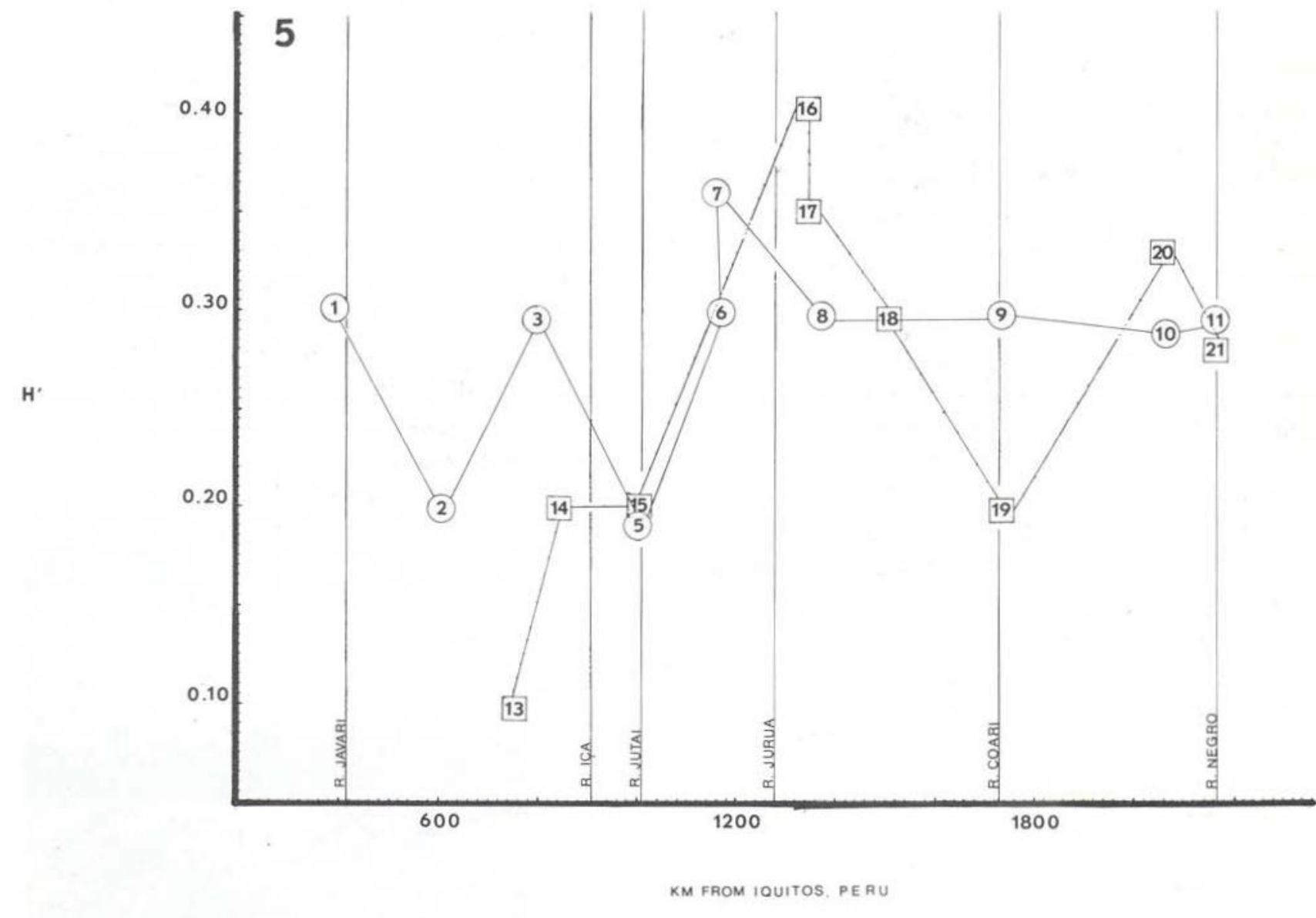

Fig. 5 - Gráfico da heterozigosidade média (H') calculada em relação à quilometragem ao longo do rio entre lquitos, Peru, e Manaus, Brasil. Os círculos representam populaçōes de Aeschynomene sensitiva var. sensitiva e os quadrados de Ae. sensitiva var. amazonica. Os afluentes foram assinalados de acordo com as marcas apropriadas da quilometragem ao longo do leito principal.

mente significantes; os resultados indicam que, em geral, a composição das duas combinações gênicas não diferem entre si. Os valores obtidos para Aeschynomene são intermediários entre os valores publicados para populações locais da mesma espécie, e para subespécies de vários organismos animais (Ayala, 1976). Carson (1976) cita exemplos críticos onde a especiação ocorreu sem alteração detectável na composição genética. A adaptação diferencial não é um pré-requisito para a especiação. Permanece a questão: Quanta diferenciação genética é suficiente para influenciar a especiação, se a evolução por seleção natural pressupōe a existência de diferenças genéticas sobre as quais as pressões seletivas atuam? $O$ presente trabalho mos- tra que (pelo menos nos loci examinados) os dois taxa de Aeschynomene apresentam valores de divergência variáveis na composição genética. Isto indica que é provável que está ocorrendo especiação ativa nessas populações ao longo do rio Solimões. O trabalho de campo também mostrou que esses dois taxa são morfologicamente distintos no habitat natural (ver diferenças na Tabela 1), e sempre foi possivel colocar cada espécime dentro de um ou outro dos taxa. A diferenciação entre os dois taxa talvez mereça reconhecimento a um grau taxonômico mais elevado do que o status varietal que Rudd (1955) Ihes atribuiu.

A Tabela 7 é a matriz dos dados sobre a identidade genética média e a distância genética média para Mimosa pigra. Este taxon 

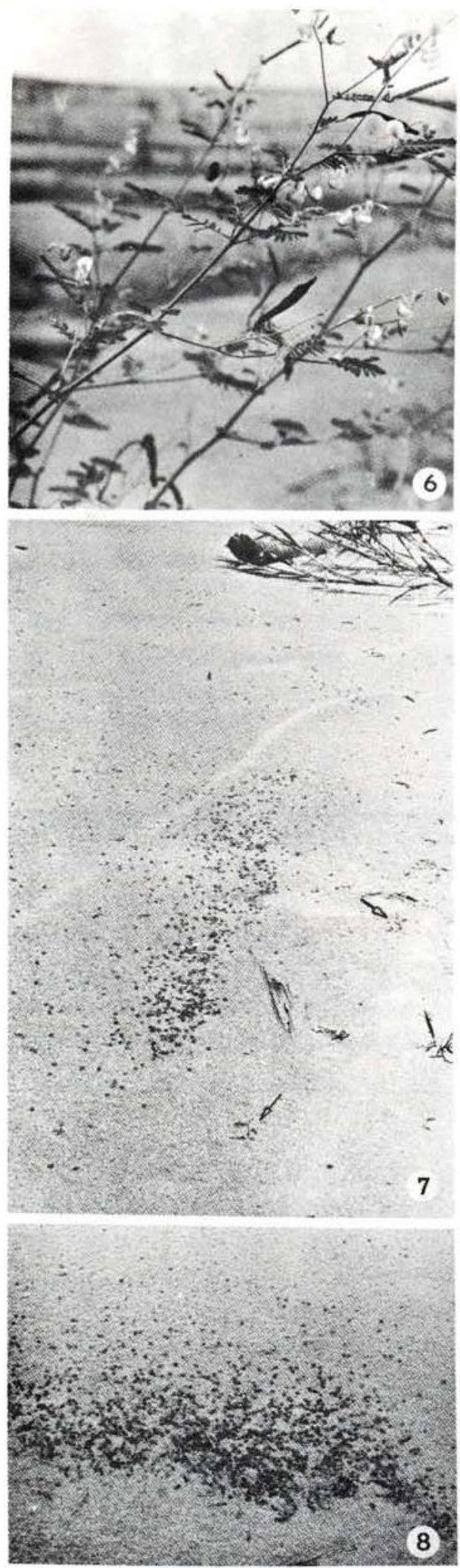
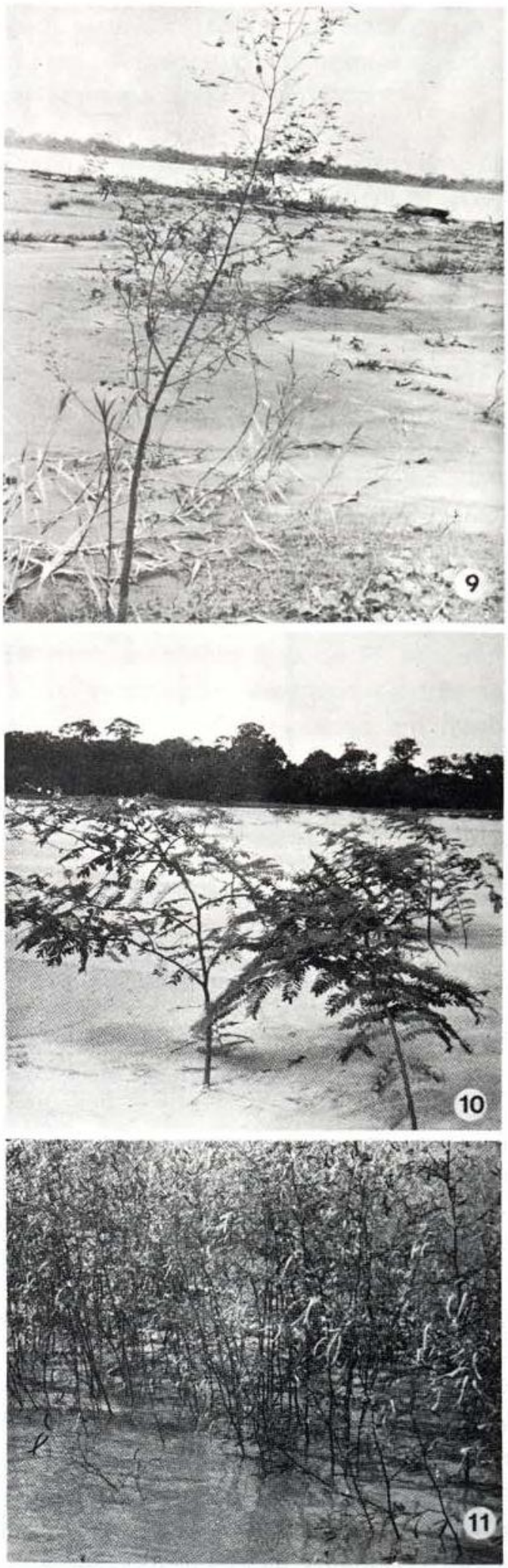

Fig. 6-11 - Fotografias de taxa e habitats ecológicos ao longo do rio Solimões. 6. Aeschynomene sensitiva var, amazonica. Sementes e lomentos de Ae. sensitiva var. amazonica sobre bancos de areia periodicamente inundados. As flech̆as destacam as plântulas jovens que germinaram e estão se estabelecendo. 9. Ae. sensitiva var. sensitiva. 10. Mimosa pigra. 11. Ae. sensitiva var. amazonica indicando inundaçăo do banco de areia enquanto o rio sobe durante a estação chuvosa. Fotografias tiradas em fevereiro de 1977. Durante vários meses do ano as plantas ficarāo completamente submersas. 
apresenta valores altos entre os dois taxa, bem como esclarecer algo sobre suas divergências evolutivas. Os valores $T$ variam de identidade completa, entre as populações 24 e $26(T=1.00)$ a $T=0.923$, entre as populações 22 e 25 . A identidade genética média de todas as populações foi 0.969 . Todos os valores comparam-se favoravelmente com os das populações locais da mesma espécie de vários organismos (Ayala, 1976).

\section{MORFOLOGIA E ESTRATÉGIAS ADAPTATIVAS}

Segundo Rudd (comunicação pessoal), é difícil distinguir entre os dois taxa de Aeschynomene com base no material de herbário, devido à plasticidade fenotípica. Entretanto, sempre nos foi possível diferenciar imediatamente os taxa no campo, através dos caracteres listados na Tabela 1. A maioria desses caracteres são diferenciais, tais como número de folíolos; se são diagnósticos, como cor ou pêlos lometares, são do tipo que se perde ou fica imperceptivel após o processo de herborização. O tamanho da semente revelou-se como característica diagnóstica depois que todas as sementes de todas nossas coleçōes foram medidas, e o número de lomentos por folículo é quase diagnóstico.

Os dois taxa também apresentam biologias e estratégias de sobrevivência bem diferentes ao longo do rio Amazonas. Embora aparentemente ambos ocupem o mesmo habitat, i.e., margens de rios sazonalmente inundadas, a adaptação dos dois é diferente. Através de experimentos de germinação e flutuação determinou-se que apenas $6.4 \%$ das sementes da var. sensitiva germinaram em 103 dias, enquanto a taxa de germinação da var. amazonica foi de $48 \%$ no mesmo periodo de tempo. Os tempos de flutuação também são significativamente diferentes entre as duas variedades. Os lomentos da var. sensitiva têm pêlos epidérmicos que retêm ar e os mantêm flutuando. Mesmo quando a água dos vasos experimentais foi perturbada, os lomentos da var. sensitiva permaneceram boiando. A germinação fica afetada somente quando a água recua e as sementes ou lomentos são atirados ao chão (Fig. 7 e 8). A var. amazonica não tem pêlos epidérmicos nos lomentos. Em 32 dias de flutuação, $41 \%$ dos lomentos afundaram (ver Tabela 1). As sementes germinaram em poucos dias, sob a água, e então vieram à tona. Os cotilédones funcionam como asas aquáticas, orientando verticalmente as plântulas e colaborando na dispersão por flutuação.

Aeschynomene sensitiva var. sensitiva é amplamente distribuída nos Neotrópicos (ver Fig. 1 e 2). A var. amazonica foi encontrada apenas nos limites mais altos do rio Amazonas, no Peru (Fig. 3), na época da monografia de Rudd (1955). O presente trabalho mostra que ela encontra-se distribuída pelo menos de Iquitos a Manaus, ocorrendo esporadicamente ao longo do rio. Conseqüentemente, as duas variedades são simpátricas e exploram o mesmo habitat de maneira levemente diferente. São necessários estudos sobre sua biologia floral e compatibilidade para determinar o quanto de diferenciação já ocorreu entre os dois taxa, revelando algo sobre suas divergências evolucionárias.

TABELA 1 - Caracteristicas taxonômicas úteis para distinguir as variedades de Aeschynomene taxa sensitiva

\section{var. sensitiva}

caules verdes e mmaterial fresco

\section{var amazônica}

\begin{tabular}{ll} 
fresco & rial fresco \\
\hline $\begin{array}{l}\text { corola amarela, sem listas } \\
\text { vermelhas }\end{array}$ & $\begin{array}{l}\text { carola amarela, com lis- } \\
\text { tas vermelhas }\end{array}$ \\
\hline $\begin{array}{l}\text { lomentos com pêlos epidér- } \\
\text { micos }\end{array}$ & $\begin{array}{l}\text { lomentos sem pêlos epi- } \\
\text { dérmicos }\end{array}$ \\
\hline $\begin{array}{l}\text { comprimento do fruto, } \\
\text { 3.0-5.0 cm. }\end{array}$ & $\begin{array}{l}\text { comprimento do fruto, } \\
4.5-8.5 \mathrm{~cm} .\end{array}$ \\
\hline $\begin{array}{l}\text { largura do fruto, } 3.0-4.0 \mathrm{~mm} . \\
\text { lomentos/folículo, } 4-9\end{array}$ & $\begin{array}{l}\text { larg. do fruto, } 4.0-6.0 \mathrm{~mm} . \\
12-14\end{array}$ \\
\hline $\begin{array}{l}\text { comprimento de semente } \\
\text { madura, 2.0-3.0 mm. }\end{array}$ & $\begin{array}{l}\text { comprimento de semente } \\
\text { madura, } 3.5-4.5 \mathrm{~mm} .\end{array}$ \\
\hline $\begin{array}{l}\text { foliolos } / \text { folha, } 20-55 \\
\text { foliolos/folha, } 10-27\end{array}$ \\
\hline
\end{tabular}




\section{DISCUSSÃo}

A tentativa de correlacionar estratégias adaptativas com variabilidade genética é arriscada. Selander \& Johnson (1973) enfatizam que a correlação das freqüências aielopáticas com fatores ambientais está longe de ser conveniente. Uma listagem de outros fatores que causam variabilidade em heterozigose gênica, além de adaptação, incluiria: auto-fecundação fluxo genético, oscilação genética em pequenas populações, número de espécies (tamanho efetivo da população), variação na amplitude do nicho (correlação entre amplitude ecológica e variação genética), migração, efeito fundador, \& articulação com outros loci sob a influência de seleção (Soulé, 1973; Johnson, 1976). Raramente é demonstrada uma correlaçăo positiva entre estratégias adaptativas e variação enzimática (Koehn, 1969; Marshall \& Allard, 1970; Merritt, 1972; Soulé et al., 1973; Selander \& Kaufman, 1973; Hamrick \& Allard, 1975; e Johnson, 1976).

A Bacia Amazônica apresenta uniformidade quanto às variáveis geográfica, geológica e climatológica (Marlier, 1973). O regime de enchentes sazonais (Fig. 9, 10 e 11) do rio é o fator mais importante que afeta a adaptação dos taxa ribeirinhos. Já foi demonstrada a relaçăo direta existente entre esse fator e o aumento da diversidade de espécies e das respostas adaptativas de peixes (Roberts, 1973). $\mathrm{O}$ regime de enchentes é unimodal na área de estudos, devido à predominância de tributários do sul sobre os do norte e ao efeito tampão da várzea (zona aluvial próxima ao rio, periodicamente inundada). Uma enchente de $15 \mathrm{~m}$. não é rara em Manaus, Brasil (Marlier, 1973). Deslizamento de terra, destruição por inundaçăo, e depósito de sementes ou plântulas frutuantes em habitats inadequados tais como os que ficam expostos com o recuo das águas promovem uma alta taxa de extinçăo entre a população dos taxa ribeirinhos. As enchentes sazonais removem uma grande parte do genoma das populações dessas regiões que sofrem variações. Uma alta taxa de atrito é evidente em todas as fases da vida da planta, de semente e adulto. As populações ribeirinhas podem ser chamadas de marginais, embora não se localizem necessariamente na periferia. Populações marginais são aqui definidas como aquelas que apresentam: flutuações relativamente altas em número de individuos e uma probabilidade aita de extinção (Soulé, 1973). As mudanças cíclicas nos valores de heterozigosidade $\left(\mathrm{H}^{\prime}\right)$ vistos na Fig. 5 resultam do equilibrio entre os altos coefi. cientes de extinção causados por restrições severas periódicas e a introdução de material genético novo pelos afluentes. O problema das condições que atrasam o progresso genético (gargalos genéticos) foi estudado matematicamente, concluindo-se que a variabilidade genética da população deve declinar rapidamente (Nei et al., 1975). O ciclo de variabilidade reduzida que se observa ao descer um afluente reflete uma população marginal e fundamenta a predição de que um alto coeficiente de extinção reduz a variabilidade genética. A heterozigosidade cíclica apoia a hipótese de que as enzimas flexíveis, funcionalmente generalizadas, são vantajosas em ambientes variáveis. Proteinas euritolerantes, espécie de enzima solitária capaz de manter as propriedades "ligand-binding" sob condiçöes ambientais diferentes, são teoricamente possiveis (Somero \& Low, 1977). O aumento na heterozigosidade (na variabilidade genética) é favorecido pelo influxo de material genético novo que vem das populações existentes ao longo dos afluentes. Isto é evidente em popúlações próximas à entrada do rio Juruá (Fig. 5, i.e., populações 16). Este rio, apresentando o maior efeito em heterozigosidade populacional, também apresenta o maior efeito em homeoestase geral de todo rio Solimc̃es-Amazonas (Marlier, 1973). O rio Juruá enche mais do que outros afluentes porque drena uma das maiores bacias hidrográficas $\left(217.000 \mathrm{~km}^{2}\right)$ na área de estudo. Também apresenta zonas de inundação e sedimentação aluvial maiores do que em qualquer outro afluente da região estudada. A var. sensitiva responde à variação sazonal do rio e às severas restrições periódicas ao tamanho da população apresentando períodos longos de flutuação, baixa taxas de germinação e menor produção de sementes. O baixo valor de $\mathrm{H}^{\prime}$ é um resultado das altas taxas de extinção causadas pela germinação 
TABELA 2 - Dados sobre as populaçōes de todos taxa examinados.

\begin{tabular}{|c|c|c|c|c|}
\hline Designaçāo da população & $\begin{array}{l}\text { Número de } \\
\text { coleçăo }\end{array}$ & $\begin{array}{l}\text { Km de } \\
\text { lquitos }\end{array}$ & Localidade & Data \\
\hline \multicolumn{5}{|c|}{ Aeschynomene sensitiva var. sensitiva } \\
\hline 1 & 24,645 & 470 & Quebrada Cayru, Peru & $3 / 3 / 77$ \\
\hline 2 & 24,640 & 619 & Belém, Igarapé Preto, Brasil & $1 / 3 / 77$ \\
\hline 3 & 24,579 & 800 & Porto Natal & $25 / 2 / 77$ \\
\hline 4 & 24,562 & 817 & Caturiapixuna & \\
\hline 5 & 24,519 & 1,004 & Ilha Barurua & $21 / 2 / 77$ \\
\hline 6 & $24,50 \overline{8}$ & 1,158 & Foz de Mamoriá, So. & $20 / 2 / 77$ \\
\hline 7 & 25,506 & 1,158 & Foz de Mamoriá, No. & $20 / 2 / 77$ \\
\hline 8 & 24,471 & 1,346 & Ananapu & $18 / 2 / 77$ \\
\hline 9 & 24,432 & 1,735 & Rio Coari & $12 / 2 / 77$ \\
\hline 10 & 24,388 & 2,065 & Manacapuru & $12 / 2 / 77$ \\
\hline 11 & 24.377 & 2.174 & Rio Negro, Manaus & $11 / 2 / 77$ \\
\hline \multicolumn{5}{|c|}{ Aeschynomene sensitiva var. amazonica } \\
\hline 12 & 24,639 & 619 & Belém, Igarapé Preto & $1 / 3 / 77$ \\
\hline 13 & 24,637 & 753 & São Paulo de Olivença & $27 / 2 / 77$ \\
\hline 14 & 24,563 & 817 & Caturiapixuna & $25 / 2 / 77$ \\
\hline 15 & 24,520 & 1,004 & Ilha Barurua & $21 / 2 / 77$ \\
\hline 16 & 24,470 & 1.346 & Ananapu & $18 / 2 / 77$ \\
\hline 17 & 24,463 & 1,346 & Ananapu & $18 / 2 / 77$ \\
\hline 18 & 24,449 & 1,514 & Tefé & $17 / 2 / 77$ \\
\hline 19 & 24,427 & 1.735 & Rio Coari & $15 / 2 / 77$ \\
\hline 20 & 24,391 & 2,065 & Manacapuru & $12 / 2 / 77$ \\
\hline 21 & 24,378 & 2.174 & Rio Negro, Manaus & $11 / 2 / 77$ \\
\hline \multicolumn{5}{|l|}{ Mimosa pigra } \\
\hline 22 & 24,662 & 470 & Quebrada Cayru, Peru & $3 / 3 / 77$ \\
\hline 23 & 24,643 & 619 & Belém, Igarapé Preto, Brasil & $1 / 3 / 77$ \\
\hline 24 & 24,588 & 800 & Porto Natal & $25 / 2 / 77$ \\
\hline 25 & 24,445 & 1,607 & Lago Tarua, Montevidéo & $16 / 2 / 77$ \\
\hline 26 & 24,430 & 1,735 & Rio Coari & $15 / 2 / 77$ \\
\hline
\end{tabular}

(*) - Todos os números de coleção são de Prance, Mori, Hill, Shimabukuru e Bernardi. Há exemplares em NY, no INPA (o material peruano está depositado em USM), e em vários outros hartários dos Estados Unidos e Brasil.

deficiente e pelo atrito entre populações que produzem menos diásporas. A estratégia adaptativa da var. amazonica é a apresentação de períodos menores de flutuação, altas taxas de germinação e produção de mais sementes (refletida em valores $\mathrm{H}^{\prime}$ mais altos). Há uma correlação entre variabilidade genética e estratégia adaptativa, segundo indicam o indice de heterozigosidade, o indice de similaridade genética, os padrões demográficos e a biologia do organismo.

O polimorfismo médio para ambos taxa de de Aeschynomene e Mimosa pigra fica entre 18 e $24 \%$ (Tabela 5). Este valor é comparável às proporções de loci polimórficos entre vertebrados "vagile" que experienciam seu ambiente como "fine-grained" (Selander \& Kaufman, 1973). A mobilidade de diásporos é maior entre essas plantas dispersas na água, as quais provavelmente também experienciam o ambiente como finamente granulado.

A identidade genética média e a distância genética média indicam que ambos taxa de Aeschynomene são estreitamente relacionados. Esses valores são próximos daqueles obtidos a nivel de subespécies por outros organismos, enquantc que Mimosa, apresenta valores comparáveis aos encontrados entre 
TABELA 3 - Freqüências gênicas (eletromórficas) em taxa de legumes (a = Homozigoto que migra com mais velocidade na corrente elétrica; $\mathbf{b}=$ Heterozigoto; $\mathbf{c}=$ Homozigoto que migra mais devagar).

\begin{tabular}{|c|c|c|c|c|c|c|c|c|c|c|}
\hline \multirow{2}{*}{$\begin{array}{l}\text { Popu- } \\
\text { lação }\end{array}$} & \multicolumn{3}{|c|}{ LAP } & \multicolumn{2}{|c|}{$\mathrm{AcPH}$} & \multicolumn{2}{|c|}{ PGM } & \multicolumn{2}{|c|}{ PGI } & \multirow{2}{*}{$\frac{\mathrm{CDH}}{\mathrm{a}}$} \\
\hline & $\mathbf{a}$ & b & c & $\mathbf{a}$ & b & a & b & a & b & \\
\hline 1 & 5.0 & 0.5 & & 1.0 & & 0.5 & 0.5 & 0.5 & 0.5 & 1.0 \\
\hline 2 & & 1.0 & & 1.0 & & 0.5 & 0.5 & 0.5 & 0.5 & 1.0 \\
\hline 3 & 0.4 & 0.6 & & 1.0 & & 0.5 & 0.5 & 0.5 & 0.5 & 1.0 \\
\hline 5 & 0.5 & 0.5 & & 1.0 & & 0.5 & 0.5 & 0.5 & 0.5 & 1.0 \\
\hline 6 & & 1.0 & & 0.5 & 0.5 & 0.5 & 0.5 & 0.5 & 0.5 & 1.0 \\
\hline 7 & & 8.2 & 0.2 & 0.5 & 0.5 & 0.5 & 0.5 & 0.5 & 0.5 & 1.0 \\
\hline 8 & 0.5 & 0.5 & & 0.5 & 0.5 & 0.5 & 0.5 & 0.5 & 0.5 & 1.0 \\
\hline 9 & & 1.0 & & 0.5 & 0.5 & 0.5 & 0.5 & 0.5 & 0.5 & 1.0 \\
\hline 10 & 0.5 & 0.5 & & 1.0 & & 0.375 & 0.675 & 0.5 & 0.5 & 1.0 \\
\hline 11 & 0.5 & 0.5 & & 1.0 & & 0.5 & 0.5 & 0.4 & 0.6 & 1.0 \\
\hline 13 & & 1.0 & & 1.0 & & & 1.0 & 0.5 & 0.5 & 1.0 \\
\hline 14 & & 1.0 & & 1.0 & & 0.5 & 0.5 & 0.5 & 0.5 & 1.0 \\
\hline 15 & & 1.0 & & 0.66 & 0.34 & & 1.0 & 0.5 & 0.5 & 1.0 \\
\hline 16 & 0.25 & 0.5 & 0.25 & 0.5 & 0.5 & 0.5 & 0.5 & 0.5 & 0.5 & 1.0 \\
\hline 17 & 0.8 & 0.3 & & 0.5 & 0.5 & 0.4 & 0.6 & 0.5 & 0.5 & 1.0 \\
\hline 18 & & 1.0 & & 0.5 & 0.5 & & 1.0 & 0.5 & 0.5 & 1.0 \\
\hline 19 & & 1.0 & & 1.0 & & 0.5 & 0.5 & 0.5 & 0.5 & 1.0 \\
\hline 20 & & 1.0 & & 0.5 & 0.5 & 0.5 & 0.5 & 0.5 & 0.5 & 1.0 \\
\hline 21 & 0.1 & 0.9 & & 0.5 & 0.5 & 0.5 & 0.5 & 0.5 & 0.5 & 1.0 \\
\hline 22 & 0.3 & 0.7 & & & & 0.5 & 0.5 & & & \\
\hline 23 & 0.4 & 0.6 & & . & & 0.5 & 0.5 & & & \\
\hline 24 & 0.5 & 0.5 & & & & 0.5 & 0.5 & & & \\
\hline 25 & 0.4 & 0.4 & 0.2 & & & 0.4 & 0.6 & & & \\
\hline 26 & 0.5 & 0.5 & & & & 0.5 & 0.5 & & & \\
\hline
\end{tabular}

populações locais da mesma espécie. As diferenças morfológicas encontradas no campo e as diferentes estratégias adaptativas dos dois taxa de Aeschynomene também sugerem a validade de um reconhecimento taxonômico mais detalhado. Deveriam ser realizados estudos complementares contexto da distribuição total e da variação de Ae. sensitiva e de espécies estreitamente relacionadas. É tam- bém importante um exame de seus cromossomos, biologia floral e compatibilidade. Não propomos nenhuma mudança formal no status taxonômico desses taxa de Aeschynomene até que sejam realizados mais estudos, mesmo porque o propósito deste trabalho foi o de determinar a variabilidade genética ao longo de um trecho do rio e não o de fazer uma investigação taxonômica detalhada. 
TABELA $4-\mathrm{H}^{\prime}=$ heterozigose m-dia, $\mathrm{H}=1.0$ $-\mathbf{x}_{i}{ }^{2}=$ cálculo da heterozigose de cada locus, $\mathbf{H}=$ $1.0-x_{i}^{2}$

\begin{tabular}{rr|rr|rr}
\hline \multicolumn{2}{c|}{$\begin{array}{c}\text { Ae. sensitiva } \\
\text { var. sensitiva }\end{array}$} & \multicolumn{2}{c|}{$\begin{array}{c}\text { Ae. sensitiva } \\
\text { var. amazonica }\end{array}$} & \multicolumn{2}{|c}{$\begin{array}{c}\text { Mimosa } \\
\text { pigra }\end{array}$} \\
\hline 1 & 0.300 & & & 22 & 0.460 \\
2 & 0.200 & 13 & 0.100 & 23 & 0.490 \\
3 & 0.296 & 14 & 0.200 & 24 & 0.500 \\
& & 15 & 0.189 & 25 & 0.373 \\
5 & 0.184 & 16 & 0.425 & 26 & 0.333 \\
6 & 0.300 & 17 & 0.360 & & \\
7 & 0.364 & 18 & 0.300 & & \\
8 & 0.300 & 19 & 0.200 & & \\
9 & 0.300 & 20 & 0.337 & & \\
10 & 0.294 & 21 & 0.285 & & \\
\hline
\end{tabular}

TABELA 5 - Indice de polimorfismo (P')

\begin{tabular}{l|c}
\hline \multicolumn{1}{c|}{ EN ZIM A } & $\left(\mathbf{P}^{\prime}\right)$ \\
\hline Ae. sensitiva var. sensitiva & \\
LAP & 0.305 \\
GDH & 0.000 \\
PGM & 0.477 \\
AcPH & 0.180 \\
Ae. sensitiva var. amazonica & \\
LAP & 0.077 \\
GDH & 0.000 \\
PGM & 0.337 \\
AcPH & 0.338 \\
Mimosa pigra & \\
LAP & 0.457 \\
PGM & 0.521 \\
\hline
\end{tabular}

TABELA 6 - Valores de identidade genética (abaixo da diagonal) e distância genética (acima da diagonal) pará 19 populaçöes de Aescynomene sensitiva (var. sensitiva, populaçōes 1-11; var. amazonica, populaçōes 13-21).

\begin{tabular}{|c|c|c|c|c|c|c|c|c|c|c|c|c|c|c|c|c|c|c|c|}
\hline & 1 & 2 & 3 & 5 & 6 & 7 & 8 & 9 & 10 & 11 & 13 & 14 & 15 & 16 & 17 & 18 & 19 & 20 & 21 \\
\hline 1 & & 0.067 & 0.003 & 0.000 & 0.154 & 0.140 & 0.077 & 0.154 & 0.007 & 0.003 & 0.126 & 0.067 & 0.175 & 0.098 & 0.109 & 0.221 & 0.067 & 0.154 & 0.139 \\
\hline 2 & 0.935 & & 0.041 & 0.067 & 0.067 & 0.078 & 0.144 & 0.067 & 0.073 & 0.069 & 0.059 & 0.000 & 0.095 & 0.123 & 0.281 & 0.134 & 0.000 & 0.067 & 0.081 \\
\hline 3 & 0.997 & 0.959 & & 0.003 & 0.124 & 0.116 & 0.079 & 0.124 & 0.009 & 0.006 & 0.100 & 0.041 & 0.147 & 0.093 & 0.132 & 0.191 & 0.041 & 0.124 & 0.116 \\
\hline$s$ & 1.000 & 0.935 & 0.997 & & 0.154 & 1.140 & 0.077 & 0.154 & 0.007 & 0.003 & 0.126 & 0.067 & 0.175 & 0.098 & 0.109 & 0.221 & 0.067 & 0.154 & 0.139 \\
\hline 6 & 0.857 & 0.935 & 0.883 & 0.857 & & 0.011 & 0.077 & 0.000 & 0.159 & 0.157 & 0.126 & 0.067 & 0.073 & 0.056 & 0.215 & 0.067 & 0.067 & 0.000 & 0.015 \\
\hline 7 & 0.869 & 0.925 & 0.891 & 0.869 & 0.989 & & 0.063 & 0.011 & 0.145 & 0.143 & 0.137 & 0.077 & 0.084 & 0.025 & 0.182 & 0.078 & 0.078 & 0.011 & 0.021 \\
\hline 8 & 0.926 & 0.866 & 0.923 & 0.926 & 0.926 & 0.939 & & $0.077^{\circ}$ & 0.082 & 0.079 & 0.203 & 0.144 & 0.150 & 0.021 & 0.032 & 0.144 & 0.144 & 0.077 & 0.063 \\
\hline 9 & 0.857 & 0.935 & 0.883 & 0.857 & 1.000 & 0.989 & 0.926 & & 0.159 & 0.157 & 0.126 & 0.067 & 0.073 & 0.056 & 0.215 & 0.067 & 0.067 & 0.000 & 0.015 \\
\hline 10 & 0.994 & 0.929 & 0.991 & 0.994 & 0.853 & 0.865 & 0.921 & 0.853 & & 0.009 & 0.090 & 0.073 & 0.135 & 0.103 & 0.105 & 0.178 & 0.073 & 0.159 & 0.145 \\
\hline 11. & 0.997 & 0.933 & 0.994 & 0.997 & 0.855 & 0.867 & 0.923 & 0.855 & 0.9 & & 0.129 & 0.069 & 0.178 & 0.101 & 0.212 & 0.224 & 0.069 & 0.157 & 0.129 \\
\hline 13 & 0.882 & 0.943 & 0.905 & 0.882 & 0.882 & 0.872 & 0.816 & 0.882 & 0.914 & 0.879 & & 0.059 & 0.026 & 0.181 & 0.304 & 0.059 & 0.059 & 0.126 & 0.140 \\
\hline 14 & 0.935 & 1.000 & 0.959 & 0.935 & 0.935 & 0.925 & 0.866 & 0.935 & 0.929 & 0.933 & 0.943 & & 0.095 & 0.123 & 0.281 & 0.134 & 0.000 & 0.067 & 0.081 \\
\hline 15 & 0.839 & 0.909 & 0.863 & 0.839 & 0.929 & 0.919 & 0.861 & 0.929 & 0.874 & 0.837 & 0.974 & 0.909 & & 0.129 & 0.251 & 0.006 & 0.095 & 0.073 & 0.088 \\
\hline 16 & 0.906 & 0.885 & 0.912 & 0.906 & 0.946 & 0.976 & 0.979 & 0.946 & 0.902 & 0.904 & 0.834 & 0.885 & 0.879 & & 80 & 0.123 & 0.123 & 0.056 & 0.092 \\
\hline 17 & 0.896 & 0.755 & 0.876 & 0.896 & 0.807 & 0.834 & 0.968 & 0.807 & 0.901 & 0.894 & 0.738 & 0.755 & 0.778 & 0.923 & & 0.245 & 0.281 & 0.215 & 0.245 \\
\hline 18 & 0.802 & 0.875 & 0.826 & 0.802 & 0.935 & 0.925 & 0.866 & 0.935 & 0.837 & 0.800 & 0.943 & 0.875 & 0.994 & 0.885 & 0.783 & & 0.134 & 0.067 & 0.081 \\
\hline 19 & 0.935 & 1.000 & 0.959 & 0.935 & 0.935 & 0.925 & 0.866 & 0.935 & 0.929 & 0.933 & 0.943 & 1.000 & 0.909 & 0.885 & 0.755 & 0.875 & & 0.067 & 0.081 \\
\hline 20 & 0.857 & 0.935 & 0.883 & 0.857 & 1.000 & 0.989 & 0.926 & 1.000 & 0.853 & 0.855 & 0.882 & 0.935 & 0.929 & 0.946 & 0.807 & 0.935 & 0.935 & & \\
\hline 21 & 0.869 & 0.922 & 0.890 & 0.869 & 0.986 & 0.979 & 0.939 & 0.986 & 0.865 & 0.879 & 0.869 & 0.922 & 0.916 & 0.912 & 0.837 & 0.922 & 0.922 & 0.98 & \\
\hline
\end{tabular}


'TABELA 7 - Valores de identidade genética (abaixo da diagonal) e distância genética (acima da diagonal) para 5 populações de Mimosa pigra ao longo do rio Amazonas.

\begin{tabular}{c|c|c|c|c|c}
\hline $\begin{array}{c}\text { Popu. } \\
\text { lação }\end{array}$ & 22 & 23 & 24 & 25 & 26 \\
\hline 22 & & 0.009 & 0.038 & 0.079 & 0.038 \\
23 & 0.991 & & 0.009 & 0.051 & 0.009 \\
24 & 0.962 & 0.990 & & 0.041 & 0.000 \\
25 & 0.923 & 0.950 & 0.950 & & 0.041 \\
26 & 0.962 & 0.990 & 1.000 & 0.959 & \\
\hline
\end{tabular}

\section{AgRAdecimentos}

Pesquisa apoiada pela National Science Foundation, bolsa $n .^{\circ}$ DEB75-03724-AO2 cedida a G. T. Prance, e pelo programa Alpha Helix da Scripps Institution of Oceanography, fase VI da Expedição Amazônica 1976-77.

Os autores agradecem ao $\mathrm{Dr}$. Warwick E. Kerr, Diretor do Instituto Nacional de Pesquisas da Amazônia, Manaus, Brasil, e a muitos de seus funcionários, pelo apoio e assistência. Agradecemos ao Cap. Feeney, ao Sr. Dennis Pop, e à tripulação do Navio de Pesquisas Alpha Helix, Scripps Institution of Oceanography, University of California, San Diego, Caixa Postal 1529, La Jolla, CA 92093. Também agradecemos ao Dr. Dominick Basile pelo uso de seu aparelho de eletroforese e de outros equipamentos em New York e ao Dr. Eduardo Lleras pela organização de muitos dos preparativos locais em Manaus, Brasil. Expressamos nossos agradecimentos à Sra. Shirley Keel, NYBG, que auxiliou nos trabalhos de laboratório, e ao Dr. Velva Rudd, Smithsonian Institution, que fez muitos comentários e identificação úteis. O presente manuscrito foi revisado pelo Dr. Daniel J. Crawford, Ohio State University, Dr. Howard S. Irwin e Sr. Rupert Barnebry, NYBG, aos quais somos agradecidos.

\section{SUMMARY}

An electrophoretic study was undertaken to determine the extent of genetic variability in three taxa of legumes (Aeschynomene sensitiva Sw. var. sensitiva, Aeschynomene sensitiva Sw. var. amazonica Rudd, Pa. pilionoideae; Mimosa pigra L., Mimosoideae) along a $2,174 \mathrm{Km}$ reach of the Amazon River from Iquitos. Peru, to Manaus, Brazil. Genetic variability was expressed in terms of : 1) degree of enzyme polymorphism ( $\left.\mathrm{P}^{\prime}\right)$, and 2) average populational heterozygosity $\left(\mathrm{H}^{\prime}\right)$. Five enzyme systems were examin€d: leucine aminopeptidase (LAP), glutamate dehydrogenase (GDH), phosphoglucomutase (PGM), phosphoglucoisomerase (PGI), and acid phosphotase (AcPH). Riverine taxa provide a unique system for the experimenta| study of population biology and evolution. The origin, perpetuation, and dynamics of genic variation within and among populations is used as an indicator of evolutionary change. Gene flow in these entomophilous, water dispersed legumes is undirectional and linear, with minor blackflow by pollen vectors. Of the enzymes examined, LAP was a monomer for all three taxa with low polymorphic values. AcPH, also a codominant monomer, had no detectable isoenzyme fraction; a situation also found in PGM systems. PGI is a very complex system controlled by several loci. GDH is monomorphic with one resolvable band. Mean polymorphism for the two Aeschynomene taxa is $21.3 \%\left(P^{\prime}=0.213\right)$, and for the Mimosa is $24.5 \%\left(\mathrm{P}^{\prime}=0.245\right)$. Average populational heterozygosity (Nei statistic, H') varied between 0.10 to 0.43 for Aeschynomene. This value was significantly higher for the Mimosa, which ranged between 0.33 and 0.50 . Heterozygosity index, genetic similarity index, demographic patterns, and biology show a concise correlation between genetic variability and adaptative strategy. Populations with a high extinction probability are more homozygous than populations with greater survival probability. Homozygosity is favored in perturbed populations along the Rio Amazonas.

\section{BIBLIOGRAFIA CITADA}

AYALA, F, J.

1976 - Genetic differentiation during the speciation process. Evolutionary biology, $8: 1-78$.

CARSON, H. L.

1976 - The unit of genetic change in adaptation and speciation. Ann. Missouri Bot. Gard., 63 : 210-223.

Davis, B. J.

1964 - Disc electrophoresis. II. Ann. N.Y. Acad. Sci., 121 : 404-427.

Dickinson, W. J. \& Sullivan, L. D.

1975 - Gene-enzyme systems in Drosophilla. New York, Springer-Verlag.

GotTlieb, L. D.

1973a- Enzyme differentiation and phylogeny In Clarkia franciscana, C. rubicunda, and C. amoena. Evolution, 27 : 205-214. 
1973b- Genetic differentiation, sympatric speciation, and the origin of a diploid species of Stephanomeria. Amer. J. Bot., $60:$ 545-553.

1976 - Biochemical consequences of speciation in plants. In: Ayala, F. J. ed. - Molecular evolution. Sunderland, Sinauer Associates inc.

HAMRICK, J. L. \& ALLARD, R. W.

1975 - Correlations between quantitative characters and enzyme genotypes in Avena barbata. Avolution, $29: 438-442$.

HARRIS, H. M. D. A.

1974 - The incidence of rare alleles determining electrophoretic variants : data on 43 enzyme loci in man. Ann. Hum. Genet., $3:$ 617-625.

HILL, R. J.

1977 - Variability of soluble seed proteins in populations of Mentzelia L. (Loasaceae) from Wyoming and adjacent states. Bull. Torrey Bot. Club, 104: 93101.

HJORTH, J. P.

1970 - A phosphoglucmutase locus in Drosophilla melanogaster. Hereditas, $64: 146-148$.

JoHNSON, G. B.

1971 - Metabolic implications of polymorphism as an adaptive strategy Science, $232: 347-349$.

1976 - Enzyme polymorphism and adaptation in alpine butterflies. Ann. Missouri Bot. Gard., 63: 248-261.

KOEHN, R. K.

1969 - Esterase heterogeneity : dynamics of a polymorphism. Science, $163:$ 943-944.

LEE, D. W. \& FAIRBRothers, D. E.

1973 - Enzyme differences between adjacent hybrid and parent populations of Typha. Bull. Torrey Bot. Glub, $100:$ 3-11.

MÁCINTYRE, R. J.

1966 - The genetics of an acid phosphatase in Drosophila melanosgaster and D. simulans. Genetics, $53: 461-474$.

MARLIER, G.

1973 - Limnology of the Congo and Amazon Rivers. In: Meggers, B. J.; Ayansu, E. S. \& Duckworth, W. D. ed. - Tropical forest ecosystems in Africa and South America : A comparative review. Washington, Smithsonian Institution press.

Marshall, D. R. \& Allard, R. W.

1970 - Isozyme polymorphisms in natural populations of Avena fatua and A. barbata. Heredity, $25:$ 373-382.

MERRIT, R. B.

1972 - Geographie distribution and enzyme properties of lactate dehydrogenase allozymes in " the fathead minnow, Pimephales promelas. Amer. Natur., 106: 173-184.

NEI, M

1972 - Genetic distance between populations. Amer. Natur., 106 : 283-92.

Nei, M.; Maruyama, T. \& Chakraborty, R.

1975 - The bottleneck effect and genetic variability in populations. Evolution, 29: 1-10.

ORNSTEIN, L.

1964 - Disc electrophoresis. I. Ann. N.Y. Acad. Sci., $121: 321-349$

ROBERTS, T. R.

1973 - Ecology of fishes in the Amazon and Congo Basins. In : Meggers, B. J.; Ayensu, E. S. \& Duckworth, W. D. ed. - Tropical forest ecosystems in Africa and South America : A comparative review. Washington, Smithsonian Institution press.

RUDD, V. E.

1955 - The America species of Aeschynomene. Contrib. U.S. Nat, Herb., 32(1) : 1-172.

Selander, R. K.

1976 - Genic variation in natural populations. In : Ayala, F. J. ed. - Molecular evolution. Sunderland, Sinauer Associates.

Selander, R. K. \& Johonson, W. E.

1973 - Genetic variation among vertebrate species. Ann. Rev. Ecology and System., 4: 75-91.

Selander, R. K. \& Kaufmann, D. W.

1973 - Genic variability and strategies of adaptation in animals. Proc. Nat. Acad. Sci., 70: 1875-1877.

SOULE, M.

1973 - The spistasis cycle : a theory of marginal populations. Ann. Rev. Ecology and System., 4: 165-187.

SOUle, M.; YANG, S. Y.; WeIleR, M. G. W. \&

Gorman, G. C

1973 - Island lizards: the genetic-phenetic variation correlation. Nature, 242: 191-193.

SOMEro, G. N. \& Low, P. S.

1977 - Eurytolerant proteins : mechanisms for extending the environmental tolerance range of enzyme-ligand interactions. Amer. Natur., 111: $537-538$.

Tripta, G.; SANtolimazza, C. \& Scozzari, R.

1970 - Phosphoglucomutase (Pgm) locus in Drosophila melanogaster : linkage and population data. Biochem. Genet., 4: 665-667.

(Aceito para publicação em 10/03/78) 